\title{
Madame de Staël, CEuvres complètes, série I, Euvres critiques, tome I, Lettres sur Rousseau, De l'influence des passions et autres essais moraux
}

Paola Sosso

\section{(2) OpenEdition}

\section{Journals}

Edizione digitale

URL: http://journals.openedition.org/studifrancesi/7968

DOI: $10.4000 /$ studifrancesi.7968

ISSN: 2421-5856

\section{Editore}

Rosenberg \& Sellier

\section{Edizione cartacea}

Data di pubblicazione: 1 juillet 2009

Paginazione: 412

ISSN: 0039-2944

\section{Notizia bibliografica digitale}

Paola Sosso, «Madame de Staël, Euvres complètes, série I, Euvres critiques, tome I, Lettres sur Rousseau, De l'influence des passions et autres essais moraux», Studi Francesi [Online], 158 (LIII | II) | 2009, online dal 30 novembre 2015, consultato il 11 janvier 2021. URL: http://

journals.openedition.org/studifrancesi/7968 ; DOI: https://doi.org/10.4000/studifrancesi.7968

Questo documento è stato generato automaticamente il 11 janvier 2021.

\section{cc) (†) $\odot$}

Studi Francesi è distribuita con Licenza Creative Commons Attribuzione - Non commerciale - Non opere derivate 4.0 Internazionale. 


\title{
Madame de Staël, CEuvres complètes, série I, Euvres critiques, tome I, Lettres sur Rousseau, De l'influence des passions et autres essais moraux
}

\author{
Paola Sosso
}

\section{NOTIZIA}

MADAME DE STAËL, CEuvres complètes, série I, Cuvres critiques, tome I, Lettres sur Rousseau, De l'influence des passions et autres essais moraux, sous la direction de Florence Lotterie, Paris, Champion, 2008, «L'Age des Lumières», pp. 423.

1 Nella «préface générale» di quest'opera tanto attesa, Michel DELON ci spiega come, dopo l'edizione completa delle opere di Mme de Staël pubblicata dopo la sua morte (Parigi, Treuttel Würtz, 1820), la scrittrice, che pure ebbe un ruolo cardine in un periodo di trasformazione culturale e politica, fu relegata alla memoria familiare e locale. Solo dopo il 1930 ha ripreso vigore lo studio e la presentazione delle sue opere. Il progetto generale della presente edizione è opera di Simone Balayé, il cui primo fine era quello di mettere a disposizione dei lettori l'insieme dei testi in una versione critica accessibile anche grazie alla scelta di adottare l'ortografia moderna.

La presentazione segue l'ordine cronologico all'interno di una tripartizione tematica: la prima, concernente le opere critiche, consterà di tre volumi di cui questo è il primo. La seconda riguarderà le opere letterarie e la terza quelle storiche. La corrispondenza sarà fornita a parte in una collana parallela della stessa casa editrice. Il primo testo presentato, le Lettres sur les écrits et le caractère de J.J.Rousseau (1788) si basa sull'edizione di Parigi del 1814: si tratta del primo testo delle scrittrice, la cui redazione si situa tra il 1786 e il 1788; è l'epoca in cui Mme de Staël inizia ad assaporare l'indipendenza, e, se i suoi giudizi risentono in parte del clima dei «salons», è innegabile 
un certo equilibrio dialettico tra la passione e la distanza critica, tra l'ammirazione e la volontà di capire. Significativo appare anche il giudizio complessivo che percepisce negli scritti di Rousseau una coerenze e un'unità di cui le Lettres ricostruiscono i vari momenti.

L'«Introduzione» alle lettere ripercorre anche le tappe fondamentali della ricezione del testo, inizialmente accolto da numerose polemiche. De l'Influence des passions sur le bonheur des individus et des nations, edito a partire dall'edizione di Parigi del 1797, pubblicato per la prima volta a Losanna nel 1796, è stato concepito in un momento di grandi «bouleversements» sul piano storico e sul piano individuale. Il testo definisce un rapporto tra le passioni e il contesto politico alla luce di due grandi forze inseparabili ed ineludibili: la ragione e la «sensibilité». L'introspezione ha come fine quello di condurre a un comportamento in grado di reagire alle nuove esigenze della storia. De l'Influence des passions, ricorda la curatrice, ha avuto una grande eco nella stampa francese e straniera dell'epoca, anche se i giudizi non erano sempre positivi. De l'Éducation de l'âme par la vie (1811), testo inedito (ms autografo degli archivi del Castello di Coppet), probabilmente progetto di un'opera «inachevée», si interroga sulle risorse morali dell'individuo domandandosi se esse derivino dalle circostanze esterne o dalla vita interiore. Si tratta di pagine che condensano alcuni temi del più celebre $D e$ L'Allemagne e in cui ritroviamo alcune riflessioni che fanno pensare a certe pagine di Corinne. L'ultima opera presentata è Réflexions sur le suicide (1813; testo base: Paris, 1814), la cui redazione coincide con un periodo in cui Mme de Staël era afflitta dalla proscrizione, delusa dalle esperienze amorose e intimorita dallo spettro della vecchiaia; la scrittrice scarta comunque la possibilità del suicidio non solo per motivi religiosi, ma anche e soprattutto perché l'accettazione del destino indica l'accettazione della propria dignità umana, che rifiuta le «complaisances» del «pathos» come anche un improbabile eroismo. Ogni testo presentato è corredato dall'apparato delle varianti; chiude il volume una «Chronologie» de Mme de Staël, una bibliografia delle opere citate e l'indice dei nomi. 